\title{
Fundamentos metodológicos para el estudio de las instituciones en la Baja Edad Media castellana
}

\author{
Regina M. ${ }^{a}$ Pérez Marcos *
}

No existe, se manifieste o se oculte, ninguna investigación históricojuridica (ni de otro campo alguno de la Historia) que carezca de una fundamentación ideológica por parte de quien la realiza. Un cierto sector de investigadores del pasado siglo, conocido como "positivismo histórico", desde que Badenheimer to bautizase asi, pretendió presentar como objeto final del análisis histórico, una exposición de hechos, sin adjudicarles ninguna significación valorativa o mejor "teleológica». La ideologia subyacente en tal propuesta se revela al considerar que se califica de "objetivo final» del historiador lo que no es sino su primer paso. Practicada esa reducción queda claro que la Historia nunca podria ser instrumento de conocimiento en cuanto que se le extirpa la crítica, y ello contribuye a consolidar las estructuras dominantes en el mundo en que el historiador vive realmente. Ese positivismo es pues, Historia ideologizada.

En consecuencia es una obligación inexcusable señalar expresamente al comienzo de todo trabajo y como primero de sus fundamentos metodológicos, la bateria conceptual que el autor ha manejado. En nuestro caso se parte de la idea de que la única Historia posible es la Historia total o Historia social, como muchos historiadores afirman, entendiendo por tal: la visión totalizadora de las diversas estructuras que integran un orden social global en un momento determinado del pasado. $Y$ en aplicación de este principio, para cualquier intento de comprensión de la His-

* Profesora Titular de Historia del Derecino y de las Instituciones. Facultad de Derecho. U.N.E.D. 
toria es conveniente usar primero de una metodologia estructuralista ${ }^{1} y$ segundo, prestar una atención especial a las conexiones ${ }^{2}$ que se dan entre las Ilamadas "formas" de la Historia: Economia, Derecho, Sociologia, etcétera (todas ellas parciales), en el seno de una Historia total.

La primera de las exigencias enunciadas comienza por la elaboración y aplicación de métodos o conceptos metodológicos o, si se quiere, en terminologia weberiana, de tipos ideales, que transportados a los fragmentos del pasado como modelos, arrojen las analogias y diferencias que los distintos campos de análisis presentan respecto a esa construcción imaginaria. Por tanto, la teoria científica de la Historia total debe de ser abordada desde un concepto que proporcione el conocimiento de la totalidad social. El concepto de “modo de producción» facilita tales características ${ }^{3}$ de investigación, tratándose de un modelo estereotipado que no existe de modo puro en la realidad, adoptado exclusivamente con fines operativos para construir un modelo teórico de análisis ${ }^{4}$.

1 Los conceptos clave como "Coyuntura" y "Estructura", etc., quedaron, tiempo atrás formulados, entre otros, en VILAR, P., Iniciación al vocabulario del análisis histórico. Barcelona 1980 .

En aplicación de las estructuras como modelo, ver: VILAR, Pierre, "thistoria social y filosofia de la historia", en Economia, Derecho, Historia. Barcelona 1983, págs. 141-161. No obstante, dada la polisemia que presenta el término «estructura», conviene aclarar que con él nos referimos a algo que designa a la vez las permanencias y las proporciones que se dan entre los fenómenos. Sobre el tema "estructuras", ver CARdoso, C. y PEREz BrignoLI, H., Los Métodos de la Historia. Barcelona 1976, págs. 49-53.

2 La palabra conexión indica el hecho de que entre los elementos de la estructura, se efectúa una relación que abarca tanto a los caracteres correspondientes a la totalidad, como a los elementos temporales. No se trata de meros enlaces lógicos, sino de interdependencias sólo comprensibles en el análisis de una totalidad histórica social que ponga de relieve el proceso dialéctico de los elementos de la estructura, en sus continuidades. Cfr. PÉrezPREndes, J. M. Una introducción al Derecho. Madrid 1974, págs. 107. En la estructura no cuentan, por tanto, los elementos singularmente tomados ni el todo indeterminado, sino la relación de los elementos entre sí.

La coherencia de la interpretación global de la realidad y de la sociedad, y en definitiva del carácter interdisciplinario del análisis histórico fue planteada como una exigencia asimismo por Catalano, F., Metodologia y enseñanza de la Historia. Barcelona 1980 (1. ${ }^{\text {ed }}$ de 1976), págs. 920. En el mismo sentido, considerando la interpretación global como punto de partida necesario: Fontana, J., en Historia, análisis del pasado y proyecto social. Barcelona 1982.

" Fionavanti, Eduardo, El concepto de modo de producción. Madrid 1974, ofrece una sintesis clarificadora de un tema tratado anteriormente de forma dispersa; ver para este punto págs. 13 y ss. Una exposición clara y útil, que puede servir de punto de partida por quedar en ella bien acotado el mencionado concepto: Hindess, B.-HiRst, P., Precapitalist modes of production. London 1975, especialmente págs. 9-20; de esta obra existe traducción al castellano: Los modos de producción precapitalistas. Barcelona 1979.

${ }^{4}$ La tentativa de pensar cientificamente la Historia, es decir, de poner al descubierto las estructuras esenciales de la sociedad explicando la razón de ser y la de sus leyes de evolución, fue acometida tanto por M. Weber como por Marx y Engels, sin que haya certeza 
Es sobradamente conocido que los tres niveles que conforman el todo complejo que es el modo de producción (la infraestructura y las superestructuras: juridico-política e ideológica), mantienen entre sí una interrelación dialéctica. La interrelación dialéctica que opera entre los diferentes niveles de estructura mencionados (siendo este el aspecto ${ }^{5}$ que más interesa resaltar aqui), es definida por el materialismo histórico como siempre $\mathrm{y}$ en todo momento determinada, en última instancia, en favor del nivel económico al que considera como motor básico del desarrollo y de cambio de la estructura social global, admitiendo muy en segundo lugar (y ello únicamente por parte de algunos autores marxistas renovadores), que cada uno de los restantes niveles de estructura presenta una existencia relativamente autónoma, con leyes de funcionamiento, de desarrollo y de investigación propias.

Convenimos en que el punto nodal para entender la Historia lo constituye el concepto de «modo de producción» que aplicado como modelo (o mejor, como concepto metodológico), forma la espina dorsal de las relaciones históricas. $Y$ de tal atribución de validez absoluta deviene necesariamente, como única via posible, una concepción materialista de la Historia, que debe ser adoptada y aplicada, no obstante, teniendo en cuenta todos los relieves y complejidades que la realidad ofrece, soslayando planteamientos unidimensioriales de acuerdo con las directrices que pueden deducirse de las propias palabras de Engels ${ }^{6}$.

absoluta de quién fue el primero. En cualquier caso, los elementos esenciales de la teoría sobre el modo de producción como modelo de análisis, se hallan si no desarrollados unitariamente, si de manera dispersa, en la obra de Marx, lo que explica que de su elaboración se hayan ocupado más los historiadores marxistas. La bibliografía sobre el análisis del concepto del modo de producción, es amplia y suficientemente difundida; como sintesis útil, entre otros: Godelier, Marx y Engels, Sobre el modo de producción asiático. Barcelona 1977, págs. 13-18; Fioravanti, Eduardo, Ops. cit. págs. 11 y, Dios, Salustiano (DE), «El Derecho y la realidad social: reflexiones en torno a la Historia de las Instituciones", H.I.D. 3 (1975), págs. 204; KuCHENBUCH, L.-MichaEL, B., "Estructura y dinámica del modo de producción "feudal" en la Europa preindustrial», Studia Historica. Historia Medieval. IV, n. ${ }^{\circ} 2$ (1986), págs. 7-59. Salamanca (publicado por primera vez en 1977 en lengua rusa); un ejemplo ilustrativo de análisis histórico en aplicación del modelo modo de producción: Monsalvo AnTON, J. M. ${ }^{a}$, «Poder político y aparatos de Estado en la Castilla bajomedieval, consideraciones sobre su problemática", Studia Histórica. Historia Medieval. IV, n. 2 (1986). Salarnanca, págs. 100-167. Y por otra parte: Weber, M., Economia y Sociedad. México 1944; VILAR, P. «Historia marxista, historia en construcción", en J. Le Goff-P. Nora (dir.) Hacer la Historia, Vol. 1. Barcelona 1978, págs. 181-219; Ibidem, en Iniciación al vocabulario del análisis histórico. Barcelona 1980, págs. 67-70, aclara y argumenta la utilidad de la aplicación del concepto de modo de producción para el análisis histórico.

${ }^{5}$ Fioravanti, Eduardo, Ops. cit., págs. 14-16. Incide en el aspecto que aqui más interesa: la relación entre los distintos niveles de estructura que conforman el concepto de modo de producción

${ }^{6}$ ENGELS, F., Carta a Bloch (21/22-IX-1890), publicada en el volumen misceláneo: «El ma- 
«... según la concepción materialista de la historia, el factor que determina la historia en última instancia es la producción y la reproducción de la vida real. Ni Marx ni yo hemos afirmado nunca nada más que esto. Si alguien lo tergiversa diciendo que el factor económico es lo único determinante, convertirá esta tesis en una frase, vacia, abstracta, absurda. La situación económica es la base, pero los diversos factores de la sobrestructura que sobre ella se levanta (...), también ejercen su influencia sobre el curso de las luchas históricas y determinan, predominantemente en muchos casos, su forma (...)".

En consecuencia, es en la infraestructura, donde hay que buscar el hilo conductor que explique los fenómenos sociales que surgen en la superestructura y consideramos que tal axioma debe de ser tomado como telón de fondo o marco general no desvirtuando en ningún caso el peso especifico de la superestructura, ya que al tiempo que los hombres producen los bienes materiales para su subsistencia van transformando sus ideas y las instituciones que las corresponden ${ }^{3}$. Por tanto, aún estando de acuerdo en que para analizar una sociedad hay que partir de la forma en que sus miembros producen los bienes materiales, más que de lo que éstos dicen o piensan, conviene ponderar en su justa medida la importancia de los distintos niveles que componen la superestructura. Ser sensible a esas grandes correlaciones y derivaciones en cada fenómeno estudiado, es lo que da la talla de cada investigación.

El carácter particular y sustantivo que la superestructura presenta respecto de la infraestructura reside, como señaló Poulantzas (basándose en la proyección de los escritos de Marx), en el hecho de que sus dos niveles (tanto el político-jurídico como el ideológico), expresan el deber-ser social por lo que deben ser captados en función de valores concretos, siempre engendrados por la infraestructura pero tan reales como ella misma ${ }^{8}$. Centrándonos pues en el análisis de la superestructura como factor de alteridad respecto al protagonismo de la infraestructura en la aplicación del modelo "modo de producción", para el conocimiento de la Historia, recordaremos que queda constituida por dos instancias: La jurídico-politica y la ideológica a las que dedicaremos atención por separado. La instancia juridico-politica, constituida por un conjunto de aparatos y normas destinado a reglamentar el funcionamiento de la sociedad con el fin de

terialısmo histórico según los grandes marxistas". Méjico 1973; y citada por Pérez-PRENDES, J. M., en Curso de Historia del Derecho Español I. Introducción y Parte General. Madrid 1978 (segunda edición), págs. 51.

Fioravanti, Eduardo, Ibidem, págs. 77-78.

" Poulantzas, Nicos, Hegemonia y dominación en el Estado Moderno. Córdoba (Argentina), 1975 (tercera edad), págs. 13. 
mantener en ella las relaciones adecuadas al modo de producción que se practica, genera la existencia de una clase o grupo dominante que ejerce su predominio sobre los demás, necesitando para ello el auxilio de un conjunto de aparatos (léase instituciones), que convenientemente ordenados permitan mantener aquella dominación ${ }^{9}$. Asi, el Estado, como una de las mencionadas instituciones, aparece como el factor de conexión formal que aglutina, utilizando al Derecho para ello, a las instancias que forman el modo de producción, y en cuya función se condensan todas las contradicciones de los diversos niveles de formación social ${ }^{10}$.

Partiendo de esta idea no parece gratuito ni faltc de fundamento, abordar el análisis histórico desde sus constantes institucionales (ya desde el ángulo jurídico, ya desde el ángulo politico) en reconocimiento del Derecho como factor de convergencia y de materialización de lineas, planteamientos y modos con que una sociedad se conduce y se ordena $y$, por tanto como elemento de interpretación histórica, en cuanto que ha sido instrumento para configurar un proyecto o programa global de la sociedad.

La importancia del Derecho en la interpretación histórica, no ha pasado inadvertida para algunos historiadores ", aunque es Pierre Vilar el que más se detiene en esta reflexióri, exponiendo que la necesidad de explicar la Historia total a través del Derecho, se justifica por ser éste el que denomina, califica, jerarquiza y consagra la acción del individuo: «Si lo económico - dice- es el corazón de cualquier estructura global y el Derecho es en efecto la cristalización del funcionamiento de las relaciones materiales, algo tendrá que decir sobre las relaciones sociales de cualquier tipo". Por ello propone ponderar qué parte corresponde al Derecho (o a la Historia del Derecho) en el conocimiento de la Historia total, realizando una labor de disección social; analizándolo como signo (revelador, testigo o exponente de las reglas de funcionamiento de una sociedad en sincronia); como consecuencia o producto de la Historia en un momento determinado; $y$, como moderador de las mentalidades que refuerzan la eficacia del sistema. Puestas de relieve las interacciones que entre Derecho e Historia total se dan, queda fijar que el estudio de ambos

\footnotetext{
9 Poulantzas, Nicos, Ibidem, págs. 68; denominó hegemonia a las características de una clase que a partir de su posición dominante en el proceso de producción, llega a imponer a) conjunto su propia concepción de las cosas.

${ }_{10}$ Fioravanti, Eduardo. Ops. cit., págs. 161-197.

$"$ Ver Perez-Prendes, J. M., Ops. cit., pág. 130 y Rehbinder, Manfred, Sociología del Derecho. Madrid 1981 (ed. en cast.), pág. 74.
} 
debe de ir necesariamente unido ${ }^{12}$. Pero no se crea que se trata aquí de aplicar al mundo jurídico una doctrina fácil y linealmente transvasable desde el mundo del materialismo histórico. A veces, como una grosera y vulgar simplificación que usa de su propia ignorancia como sedante, se ha intentado descalificar cualquier referencia al materialismo histórico, mediante la simple acusación de "marxismo". Mas, ¿de qué marxismo se habla?

Se suele ignorar la importancia del Derecho como complejo fáctico de la acción humana real, sin solución de continuidad con los demás órdenes sociales, y como tal, válido para el análisis histórico, que no es aceptada por algunos historiadores de adscripción marxista, para quienes el Derecho es únicamente la apariencia (y sólo eso), o el disfraz de la ideología en su peyorativo sentido de ocultación de la realidad ${ }^{13}$. Esta minusvaloración del Derecho dentro del conjunto de factores que pueden darnos la explicación total de la Historia, resulta una simplificación, como ha demostrado Salustiano de Dios ${ }^{14}$, teniendo en cuenta que el Derecho, según

${ }^{12}$ Son referencias metodológicas importantes: VILAR, Pierre. "Historia del Derecho, historia "total"”, en Economia, Derecho, Historia. Barcelona 1983, págs. 119-137, tambièn publicado en Revista de Historia del Derecho. I (1976), con el título "Histoire du Droit Histoire totalı; este trabajo se encuentra, a su vez, sintetizado en CArdoso, C. y PÉrez BrignoLI, H., Historia económica de América Latina, I. Barcelona 1984, Cap. 1, págs. 11 y ss.; GARCIA DE CORTAzAR, J. A., "Los nuevos métodos de la investigación histórica", Boletin informativo de la fundación Juan March, n. 41 (Madrid 1975), págs. 3-17.

${ }^{13}$ En efecto, no cabe negar el ancestral divorcio entre Derecho y pueblo, pero que sin duda se fundamenta en otro tipo de causas como la oscuridad del lenguaje técnico de las normas (ver para este punto: Pérez-Prendes, J. M., Ops. cit., págs. 151-159); o la ambivalencia de algunos contenidos jurídicos.

Para el tema Derecho e ideologia se dispone de una amplia bibliografia, de la cual sólo se reseña aqui la que se considera útil y suficiente para abordar el aspecto general del tema, independientemente de que a lo largo del trabajo, y ya de manera dispersa, se cite otra aplicable a aspectos puntuales: como punto de partida resulta indispensable la lectura de KELSEN, quien vio la relación que, en efecto, existia entre ideología y Derecho pero señalando también que las normas tienen una existencia ideal, diferente de la existencia real. Esta cuestión y otras relacionadas, en: Esquivel PÉREZ, Javier, Kelsen y formalismo y realis. mo en la teoria del Derecho. México (Universidad Nacional Autónoma), 1980, págs. 46-47; Gramscl, A., El materialismo histórico y la filosofia de Benedetto Croce. Buenos Aires 1973 (riotas y reflexiones sobre algunos temas centrales del marxismo, entre ellos sobre la ideologia); LaLinde Abadia, J., "Hacia una Historia paralógica del Derecho", H.I.D. 4 (Madrid 1977), págs. 317-353; Ibidem, "La Historia del Derecho ante la Historia social", en H.I.D. 1 (1974); Clavero, B., "Historia, Ciencia, Politica del Derecho". E. Q.f. 8 (1979), págs. 5-58.

${ }^{14}$ Dios, Salustiano (DE), "El Derecho y la realidad social...", Art. cit., pág. 189. Y también Pérez-Prendes, J. M., Ops. cit., pág. 132. Asi mismo, este problema ha sido detectado por GonzÁlez Alonso, B., "Notas sobre las relaciones del Estado con la Administración señorial en la Castilla moderna", A.H.D.E., 53 (1983), p. 378: "Nadie ha reivindicado nunca para el Derecho el papel de protagonista absoluto de la Historia. El factor juridico es considerado uno entre varios y generalmente no el fundamental. El error estriba en adjudicarle a priori 
la propia teoria clásica marxista es parte tanto de la infraestructura (formada por las relaciones de producción y también por su expresión juridica, o sea, las relaciones de propiedad), como de la superestructura ${ }^{15}$. La utilidad que proporciona la Historia del Derecho al historiador estriba en que, por ser este una creación del hombre en sociedad, debe ser entendida y estudiada en relación con el resto de las formas culturales que elaboran los mismos hombres que le dieron vida, esto es, en aplicación de un transplantado fenómeno de vasos comunicantes. Por lo que se refiere al estudio que aqui se presenta, las fuentes utilizadas, por ser fuertemente ideologizadas, guardan por esta via un estrecho parentesco con la Historia del Derecho.

Para completar la linea argumental que sirvió de punto de partida, queda exponer la importancia analitica que puede concederse, de acuerdo con nuestro planteamiento, al otro nivel que conforma la superestructura, es decir, a la instancia ideológica. La superestructura ideológica comparte con la superestructura juridico-politica la atribución de validez metodológica para abordar el análisis histórico; difiere de aquella en cambio, en que se ajusta a un concepto no fácil de captar.

Son muchas las definiciones que pueden encontrarse en la historiografia acerca del concepto ideologia ${ }^{16}$ : pero lo que aqui interesa es el

una posición accesoria e inalterable en el entramado histórico, en sofocar su eventual dinamismo, menospreciando ab initio su aptitud, para situarle en diversos emplazamientos. Es lo que ocurre cuando 10 encerramos dentro de los sucesivos modos de producción, en los que irremediablemente la instancia juridica en su más amplio sentido queda relegada a un lugar secundario y derivado.

Por su parte, las objeciones principales que suscita la concepción marxista del Derecho, se encuentran bien sistematizadas en Pérez-Prendes, J. M., Ops. cit., pág. 74; y el mismo autor en Curso de Historia del Derecho Español. I. Introducción y parte general. Madrid 1978, pág. 109.

${ }^{15}$ Pérez-Prendes, J. M., "Sobre el conocimiento histórico del Derecho", en Estudios de Deusto XVII, N. 36-38 (1969), pág. 367.

${ }^{16}$ LuMIA, G., Principios de teoria e ideologia del Derecho. Madrid 1978 (Ed. en castellano), págs. 138-140: el uso actual del término proviene de Marx que la utilizó para indicar los sistemas de ideas, de opiniones y de creencias tendentes a justificar las posiciones de clase, contraponiéndola a la idea de teoria como ciencia falsa, fundada sobre presupuestos imaginarios y no sobre la realidad de las cosas. Queda con ello consagrado el significado peyorativo del término ideologia y fijado como sinónimo de enmascaramiento de intereses.

Posteriormente MANNHEIN (en Ideologia y Utopia) interpuso al concepto asi fijado un matiz diferente al determinar que todo el pensamiento humano aparece condicionado por la visión del mundo propia de cada época, con lo que sustituye el significado peyorativo del término ideologia, por un significado no valorativo usado para indicar una caracteristica permanente $e$ ineliminable del saber humano en cuanto tal. En tal seritido ideologia es un sistema de ideas, opiniones y creencias compartidas por los miembros de una colectividad.

Pérez-Prendes, J. M., en la obra citada en la nota 2 Supra,, define ideologia siguiendo a 
análisis de las ideologías en función de su articulación, y de sus procesos de dependencia. Este punto de vista se ve plenamente refrendado por Althusser (y sus seguidores) cuya aportación supone una rectificación (tras una nueva lectura) de los planteamientos marxistas al afirmar que la reproducción de un sistema sólo queda segurada con la aplicación de una ideología: la ideologia dominante. Tal compenetración desemboca sin remedio en el sometimiento a esa ideologia. Según esto, la presencia de una ideología como estructura presente en todos los sistemas, resulta tan evidente como real ${ }^{17}$. Para Althusser ${ }^{18}$, toda práctica se desenvuelve en un medio ideológico, asignando asi a la ideología la atribución de cumplir una función de conexión del todo social. Ideología es una especial actitud del hombre frente a la realidad especifica; es además una actitud intencional como la de toda conciencia, aspecto ya puesto de relieve por los escolásticos. Es una relación imaginaria de los individuos con sus condiciones reales de existencia, es decir, un conjunto de representaciones pero también de prácticas y comportamientos conscientes o inconscientes.

Sintetizando, la significación actual ${ }^{19}$ de ideologia se ajustaria al siguiente enunciado: es una interpretación deformante de la realidad social que no sólo constituye una "falsa teoria" sino que además modaliza y distorsiona determinados contenidos con el fin de ocultar algunas connotaciones de la realidad o de adjudicarla características que no tiene ${ }^{20}$. La importancia de la ideología, como un concepto más amplio que el de mentalidad ${ }^{21}$, en el conocimiento de lo social, quedó evidenciada desde

Athusser, como el sistema de representaciones que dominan el espiritu de un hombre o de un grupo social, que a su vez constituye una parte integrante de la estructura social y que ofrece una representación de esta totalidad social a la mente de los individuos que la viven quienes se la representan como una percepción objetiva de la realidad exterior a ellos.

Para Dubr, G., en Los tres órdenes o lo imaginario del feudalismo. Barcelona 1980 (Ed en castellano), pág. IV, ideologia es un sistema de representaciones que posee un rigor, una existencia y una función histórica en el seno de una sociedad.

Asi mismo, sobre la teoria de las ideologias, sigue siendo de gran utilidad: WELzEL, H., Introducción a la Filosofia del Derecho. Madrid 1971.

1) Gramsci, A., Ops. cit. Supra, en nota 13, págs. 55 a 64 y 245 a 246. $9-15$.

16 Althusser, Louis, Ideologia y aparatos ideológicos de Estado. Buenos Aires 1970, págs.

!9 El vocablo ideologia al parecer no tuvo hasta comienzos del siglo xix ninguna formuIación que pudiera hacer referencia a una ontologia de la realidad social; esta significación nace y se difunde cuando Napoleón Bonaparte al referirse a las críticas que su politica imperiaiista suscitaba en los ideólogos alemanes, adscribió al término un matiz despectivo con el evidente propósito de poner de manifiesto el alejamiento de la realidad politico social francesa que tales criticas implicaban.

20 Mendez de Smith, E., Las ideologias y el Derecho. Buenos Aires 1982, págs. 39-61.

${ }^{2}$ Vovelle, M., en Ideologias y mentalidades. Barcelona 1985, págs. 15 y ss., matiza la diferencia que existe entre los conceptos de ideologia y mentalidad. 
el momento en que se advirtió la posibilidad de un desvio entre la realidad y su correspondiente expresión conceptual; y al quedar probada la posibilidad de una falsa conciencia de lo real. Así, lo que llamamos ideología se presenta con un origen y una función empiricos, y puede, como estructura, aspirar a construir una interpretación coherente de la realidad enmarcando las contradicciones internas y los intereses de clase o de grupo que subyacen en la articulación de sus proposiciones ${ }^{22}$.

Las ideologias se caracterizan, según Duby, por estar sometidas a unos ritmos de cambio que difieren de los que afectan a las estructuras materiales presentándose entre unas y otras una clara diacronia que debe de ser tenida en cuenta. Al mismo tiempo son altamente resistentes al cambio y a menudo actúan como traba de las modificaciones. Se trata por último de estructuras latentes que no son un reflejo de lo vivido sino un proyecto de acción sobre ello (aunque para que la acción tenga alguna posibilidad de ser eficaz la disparidad entre la representación imaginaria y las realidades no debe ser demasiado grande) ${ }^{23}$.

Asimismo, cabe asignar a la ideología como objeto empirico que es, una cierta tipologia ${ }^{24}$ que establezca, cuanto menos, la diferencia que se da entre aquellas ideologías Ilamadas "orgánicas", que cuentan con un peso o una influencia considerables dentro del conjunto social: entre las que hay que citar la ideología del Estado ${ }^{25}$ y, a la ideologia del grupo dominante ${ }^{26}, y$, otras ideologias que llamaremos «inorgánicas» entre las que se cuentan las "minoritarias" (individuales o de partido) o las denominadas "deseadas" por considerarlas saludables para el sistema, ya que en ellas se proyectan con frecuencia las transformaciones futuras. De entre la diversidad de ideologias, que lógicamente pueden coexistir dentro del mismo sistema, interesan aquí aquellas que se ofrecen de una

22 Elorza, Antonio, "Las ideologias politicas y su historia", en Boletin Intormativo de la Fundación Juan March. (Diciemb. 1975), págs. 6-16.

${ }^{23}$ Duby, G., Ops. cit., págs. IV y V.

${ }^{24}$ Esta sencilla tipologia que sobre la marcha se ha elaborado, lejos de ser exhaustiva ni tampoco válida para otros enfoques, pretende sólo simplificar la exposición y al paso señalar las ideologias llamadas orgánicas, por cuanto que va a ser en ellas donde nuestra atención se centre.

${ }^{25}$ El Estado, como señaló Althusser, es un sujeto activo en la formación y emisión de ideologias mediante las que intenta consolidar su poder condicionando en beneficio propio la producción de signos dentro del sistema social.

${ }^{26}$ Cada fracción social, en función de su propia situación en el modo de producción, posee una conciencia propia y especifica; asi el grupo dominante acaba monopolizando las ideologias de los otros grupos sociales al igual que el modo de producción, de modo que el reparto de la renta social se justifica elaborando con la ayuda del Derecho una ideología determinada. Ver, Fioravanti, E., Ops. cit., págs. 203-216; y Kula, Witold, Problemas y métodos de la Historia Económica. Barcelona 1977 (tercera Ed.), pág. 133. 
manera más clara como punto de mira para observar la articulación que se opera entre las estructuras y las superestructuras.

El concepto de ideologia presenta, no obstante, ciertos peligros a la hora de ser manejado para abordar el análisis histórico tratando de ver qué relación mantiene (la ideologia) con lo concreto y real de las relaciones sociales. De entre tales peligros el más evidente es su tendencia al reducionismo y a la simplificación ${ }^{27}$. Por ello, el tratamiento de las ideologias debe acompañarse de algunos interrogantes como: quién es el emisor de la ideología dominante; cuáles son sus condiciones económicas; si representa la opinión de la mayoría de los miembros de un grupo determinado; si la manipulación que se ejerce a través de la ideologia dominante es consciente o inconsciente; cual es el nivel de interferencia del Estado en el proceso de producción ideológica; qué métodos se utilizan para su difusión ${ }^{28}$. Otra cuestión a considerar es la naturaleza específica que presenta el discurso ideológico, esencialmente contrapuesto al discurso científico por tener una función valorativo-directiva; por no ser deducible, experimentable ni verificable; porque entierra sus raices en el fondo emocional de la naturaleza humana dirigiéndose al sentimiento y no a la inteligencia ${ }^{29}$.

En definitiva, el tratamiento más adecuado que, de las ideologias debe hacerse, consiste en observar a través de ellas, las relaciones que se dan entre lo material y lo mental, superando el contenido explicito de las representaciones para alcanzar su verdadero significado. El historiador, como señaló Duby, debe criticar y desmitificar las ideologias en función de las realidades materiales, en función de lo que ocultan, y de lo que callan ${ }^{30}$, leyendo por detrás de los sistemas de valores, tan frecuentes $y$ claros en la literatura cronistica, las realidades de la explotación.

\footnotetext{
${ }^{27}$ Quienes lo aplican acaban a menudo afirmando que las ideologias son siempre un mecanismo para mantener a la clase dominante en el poder.

${ }^{28}$ Este punto ha sido tratado por Elonza, A., Art. cit., págs. 8-10; y Burke, Peter, Sociologia e Historia. Madrid 1987 (Primera Ed. castellano), pág. 98. El primero de los cuales incide además en la importancia de diferenciar netamente las ideologias de las mentalidades a las que define como conjunto de manifestaciones del comportamiento colectivo, mientras que las ideologias son sus representaciones articuladas (por lo que pueden constituir un sector de la Historia).

No obstante, mentalidades e ideologias mantienen entre si fuertes vinculos y entre ellos hay que mencionar que juntas constituyen una alternativa válida a lo que Duby denominó "excesos de la Historia Económica", al hacer mención de la atribución a esta de único factor de análisis histórico válido.

${ }^{29}$ Lumia, G., Ops. cit., págs. 140-142.

${ }^{30}$ Duby, G., Ops. cit., págs, IV-V.
} 
A modo de conclusión de lo hasta aquí expuesto, puede decirse que, asumiendo la importancia sustantiva de la infraestructura como elemento de análisis histórico, se cree al mismo tiempo que es necesario resaltar la importancia de las superestructuras que deben ser reivindicadas y aceptadas como referente obligado si se pretende acceder a un conocimiento total de la Historia. De no ser asi, sólo los análisis económicos harian Historia, siendo cierto que la estructura de una sociedad no depende solamente de su sistema de producción por estar estrechamente emparentada con la forma en que tal sociedad toma conciencia de si misma. Considerar los fenómenos sociales como simple prolongación de los económicos, es reducir el campo de interrogantes $y$, es renunciar a percibir claramente ciertas lineas de fuerzas esenciales ${ }^{31}$.

Un análisis diseccional de la sociedad castellana en los origenes de la Edad Moderna desde la perspectiva de la élite nobiliaria como vértice del poder, que busque revelar el grado de unidad o división de sus componentes, sus relaciones internas y externas y, sus sistemas de reclutamiento, resulta sugestivo por la amplitud de sus vinculaciones y también porque esa sociedad es el contexto que mejor refleja la contradicción que implica que una estructura arcaizante acabe adaptándose a un orden nuevo.

Con frecuencia se ha abordado el tema de las aristocracias partiendo de la consideración o del prejuicio inconsciente de que son un grupo antipático y parasitario. Pero es preciso desterrar tal maniqueismo, basado en un liberalismo ingenuo, y dejar de ver en la nobleza todo el mal y en el resto de las estructuras sociales todo el bien. Por lo que a sus relaciones con la Corona se refiere, ignoramos qué hubiera ocurrido si la monarquía hubiera impuesto su fórmula de total predominio $y$, por lo que a otras estructuras respecta, hay que reconocer que se adecuaron al modelo establecido en la mayor parte de las sociedades preindustriales de Europa y no es razonable suponer que no prestara la aristocracia un servicio útil.

Es casi imposible que la nobleza castellana sea examinada nunca como un todo. La complejidad de los problemas inherentes a su estratificación, la variada escala de las fortunas y de los grados de poder, los diferentes niveles de la nobleza, etc., dificultan un estudio global, aunque ello no signifique que no puedan hallarse puntos comunes dentro de un abanico de situaciones diferentes. Un grupo social consta de un número de individuos, cada uno de los cuales es un ser humano, aunque está

${ }^{31}$ Dusy, G., Hombres y estructuras de la Edad Media. Madrid 1978, pág. 244. 
claro que cada uno de los nobles no se iguala por serlo a los demás miembros de su grupo: significación familiar, poder económico, habilidad política, etc., diluyen de hecho esa igualdad en cuanto meros sujetos, pero no del todo. Cada caso es pues, una variante parcial de lo que se estima como norma. La medida estadistica seria así un medio inicial para comenzar el análisis del caos que ofrecen las conductas personales y facilitaria luego, al aplicar esas otras variables que acaban de citarse, llegar a descubrir lo que es una muestra típica y lo que se aparta de un modelo prevalente. No haber aplicado esos controles puede haber llevado a generalizaciones inadmisibles basadas en unos cuantos ejempios destacados. Pero no debe olvidarse que la conducta individual y de grupo a menudo se mueve por resortes más sutiles que los que pueden revelar las tablas estadisticas y las declaraciones y actos de los sujetos. El tratamiento de un tema nobiliario tampoco ha de limitarse a la catalogación de personajes basada en datos aportados por los archivos privados, que favoreciendo éxitos a expensas de los fracasos, pueden conducir a la simplificación, partiendo de una selección de casos que podria resultar demasiado pequeña y conllevar prejuicios. Parece que los ambientes nobiliarios pueden abordarse desde otra perspectiva que se sitúa más que en los casos concretos, en la referencia constante de las esferas del poder, respecto al marco histórico. Si la visión de la nobleza no puede ser unificadora, si puede serlo su respuesta ante un planteamiento de fondo como el que se dio con el Estado Moderno.

Este enfoque obedece a un doble punto de partida: la consideración de que la situación que la nobleza presentó en un momento determinado (en el que comienzan a hacerse visibles las fisuras del modo de producción feudal), es un reflejo de la disposición del resto de las fuerzas sociales y, de la conciencia en el investigador de que la dialéctica que se dio entre nobleza y monarquia en la baja Edad Media, no fue exclusiva de Castilla y León, por tanto, su trayectoria respondió a unas constantes que la determinaron desde más allá de su propia casuistica.

Un criterio metodológico especifico debe de orientar los estudios de la nobleza como ya señalaron Moxó ${ }^{32}$, Ladero ${ }^{33} \mathrm{y}$. Stone ${ }^{34}$, que en primer lugar ha de aplicarse a un periodo cronológico que posea criterio

${ }^{32}$ Moxo, S., "La nobleza castellano-leonesa en la Edad Media". HISPANIA, XXI (1961); "Los señorios, cuestiones metodológicas que plantea su estudio", A.H.D.E. (1973); y, "Los señorios, en torno a una problemática para el estudio del régimen señorial», HISPANIA, 94 (1964).

${ }^{33}$ Ladero Quesada, M. A., «Aristocratie et régime seigneurial dans l'Andalousie du xv siecle", Annales E.S.C. (nov.-dic. 1983).

${ }^{34}$ Stone, L., La crisis de la aristocracia 1558-1641. Madrid 1976. 
Fundamentos metodológicos para el estudio de las instituciones ...

valorativo propio $y$, en segundo lugar debe ser aplicado a las distintas realidades geográficas que presenten matices diferenciales.

El análisis de ciertos comportamientos de la nobleza castellana en el tránsito de la Edad Media a la Moderna que se aborda en el presente trabajo, responde al intento de ayudar a despejar una serie de cuestiones que se han considerado nodales a la vista de lo anteriormente dicho. Asi, por ejemplo, cabe preguntarse: ise dio un planteamiento moderno de Estado contra el que enfrentó una nobleza que constituía una élite social, una élite de riqueza y una élite de poder y que como tal era el máximo representante de la medievalidad? $Y$ dado que a lo largo de todo el Antiguo Régimen con la supremacía de la tierra permanece el respeto a los ideales aristocráticos ¿dónde se resuelve la contradicción que entraña el despegue paralelo del Absolutismo y el reforzamiento de los privilegios? Además: ¿cuáles eran las bases ideológicas y políticas que se sentaron durante el reinado de los Reyes Católicos y que perduraron después? Algunas reflexiones a partir de noticias ya publicadas y una interpretación de las causas que permitieron a la nobleza castellana consolidar su preeminencia dentro de una circunstancia histórica, teóricamente adversa, conforman una visión de campanario que se acomete a partir de dos propósitos iniciales: describir lo más completamente posible el entorno de la nobleza en sus aspectos material y económico y, destacar la influencia que ejerció en la evolución de las instituciones de la monarquía centralizada.

La recepción del Derecho común en Europa conllevó la aceptación de una redistribución del poder, dentro del Estado, en favor de las clases nobiliarias. El aparato del Estado quedó organizado de acuerdo con este arquetipo, puesto que justificaba en esencia un régimen de privilegios sobre el que se asentaba la propia monarquía. La integración de la nobleza teudal en el Estado Moderno, prevaleció en Occidente con carácter supranacional en forma de adquisición de cargos y privilegios, de ahi que un intento de sistematización de las relaciones entre nobleza y monarquia en esta época, resulte sugestivo.

La reafirmación del sistema politico feudal dentro del proceso de formación de los Estados Modernos no transformó la relación entre nobleza y monarquia en ningún sentido unilateral. La creación y remodelación de instituciones que, tenia como objetivo la ampliación de la base fiscal de la monarquia, al mismo tiempo incrementó el potencial control de la nobleza sobre el sistema intentando la reproducción del equilibrio feudal dentro de un marco más complejo y eficaz. El contraste entre lo medieval y lo moderno resulta en este sentido menos acusado de lo que puede parecer, pues la centralización supuso para muchos nobles otra oportu- 
nidad de fortuna y fama. Cierto es que la centralización monárquica descansó en buena medida sobre los servicios burocráticos a cargo de nuevos grupos sociales, pero también lo es que la nobleza supo adaptarse y se sumó a la carrera burocrática (sobre todo en la modalidad diplomática) en un intento tenaz de no romper su vínculo con la realeza. Pero el camino hacia el absolutismo habia podido resultar más corto para la monarquia si la nobleza hubiera desempeñado de otra forma su papel. Cabe pues en este sentido, hacer una valoración del fenómeno que puede no ser absolutamente negativa si se vincula a la pregunta ¿cuál hubiera sido la ordenación de las fuerzas socio-politicas en caso de que la tendencia de la monarquia hacia el absolutismo no hubiera encontrado obstáculos en su camino? Desde luego, una disposición vertical presidida por un vértice monárquico habia desplazado a la que con el tiempo habria de ser horizontal. Tanto una como otra fuerza se vieron obligadas a adaptarse: la nobleza se vio obligada a abandonar sus viejas tradiciones y a adquirir nuevos saberes; la monarquia por su parte, hubo de admitir los sofocantes privilegios nobiliarios. Pero el aumento del poder político de la monarquia no vino acompañado por una disminución de la seguridad económica de la propiedad nobiliaria de la tierra sino por un aumento paralelo de los derechos generales de la propiedad privada. El camino hacia el absolutismo no significó en esta fase el fin del dominio de la nobleza hereditaria en Europa. Los reyes de las nuevas monarquias nunca pudieron transgredir los invisibles limites del poder aristocrático, es decir, los límites de las condiciones materiales de reproducción de la clase a la que ellos mismos perterecian ${ }^{35}$. La colisión frontal entre ambas nunca llegó a producirse y el efecto de su mutua adaptación fue la eliminación de los poderes intermedios que existian entre la corona y la nobleza que quedaron absorbidos por la nobleza. Las asambleas representativas se hundieron a medida que el poder nobiliario actuaba como fuerza centripeta bajo la enseña real ${ }^{36}$. Otro tanto ocurria con la administración local en concejos y municipios, cuyos cargos de gobierno pasaron a ser patrimonio exclusivo de los linajes nobiliarios ${ }^{37}$.

35 Anderson, Perry, Op. cit., pág. 441, y DıOS, S. (DE), "Sobre la génesis y los caracteres del Estado Absolutista en Castilla», Studia Histórica. Historia Moderna III. (Salamanca 1985).

36 Fernandez Alvarez, La sociedad española del Renacimiento. Salamanca 1970, págs. 1927 .

${ }^{3 i}$ Monsalvo Anton, J. M. a , El sistema politico concejil. El ejemplo del señorío de Alba de Tormes y su señorio de villa y tierra. Salamanca 1988, especialmente los capitulos 1 y 2 de la 1. ${ }^{\text {a }}$ parte, págs. 26-36. Ibidem, "Poder politico y aparatos del Estado en la Castilla bajc medieval. Consideraciones sobre su problemática", en Studia Histórica. Historia Medieval. IV, n. 2 (Salamanca 1986), págs. 100-167. 
La proximidad y concatenación existentes entre los fenómenos Estado Moderno y Renacimiento, subrayada por el profesor Maravall ${ }^{38}$, hace a cada uno de ellos punto de referencia necesario para tratar del otro. Pero al no ser nuestro propósito el estudio del Renacimiento, baste decir en una aproximación genérica que se trata en un principio de un amplio movimiento cultural y artistico cuyas repercusiones transforman la politica y la sociedad por cuanto que está inscrito en una concepción antropocéntrica del mundo. El marco geográfico-temporal del Renacimiento es la Italia de la Edad Moderna, aunque tiene sus raices en lo medieval. Así es que en la relación entre Estado Moderno y Renacimiento, se encuentra un reflejo ambivalente de causa efecto. El profesor Maravall definió el Renacimiento como el periodo de cambios estructurales que se presentaron en las ciudades europeas, no todos ni en todas las partes ${ }^{39}$, de la misma profundidad conexos con el proceso de formación del Estado Moderno ${ }^{40}$. Creemos por tanto, que es el Renacimiento el que marca las pautas necesarias para la aparición del Estado Moderno, en cuanto que se trata de un fenómeno más generalizante. En cualquier caso, ambos fenómenos son la manifestación de unos puntos de partida comunes, englobados en la concepción antropocéntrica del universo.

Pero más que la esencia del fenómeno renacentista es de nuestro interés el análisis de sus efectos: en el "campo politico", Renacimiento se traduce en una creciente tendencia a la concentración de poder en manos del monarca frente a la dispersión en diferentes parcelas de poder características de la etapa feudal; trajo consigo una nueva lógica del poder. En el "campo económico", Renacimiento significa racionalización de la técnica comercial así como la proliferación del hombre de empresa. Ambos factores transforman el desarrollo de la economía de etapas precedentes. En el "aspecto social", Renacimiento significa la aparición de nuevos tipos humanos, con lo que el perfil triangular de la sociedad medieval, compuesta por caballeros, clérigos y campesinos, queda desfigurado. Estos nuevos tipos humanos, de extracción burguesa y urbana, tienden a conformar la sociedad a la medida de sus necesidades. En el "campo ideológico", el Renacimiento se traduce en incipiente racionalismo y espíritu crítico. En lo tecnológico, el Renacimiento está representado por el invento y uso de la imprenta. En el campo lingüístico, esta es la época en que las lenguas romance se transforman en lenguas cultas de las cien-

\footnotetext{
3 Maravall, J. A., Estado Moderno y mentalidad social. 2 vols. Madrid 1972.

39 Maravall, J. A., "La fórmula del Renacimiento español", en Estudios de Historia del Pensamiento Español. Serie segunda: la época del Renacimiento. Madrid 1984, págs. 75107.

4o Maravall, J. A., Carlos V y el Renacimiento. Madrid 1960.
} 
cias y también de las Cancillerias, disputando al latín el monopolio cultural que habia ejercido. En el campo cultural se opera la secularización del saber ${ }^{41}$ : en adelante, no va a ser la Iglesia la única que se dedique al estudio, ya que entre las filas del nuevo estrato burgués, va sedimentando la riqueza y con ella el ocio y la posibilidad de dedicarse a inquietudes culturales. La aparición de estos nuevos tipos humanos dentro del espectro social, resulta de particular interés en la medida en que aporta savia nueva. Nos referimos a los JURISTAS, quienes dada su preparación jurídica pronto serán elementos necesarios para los reyes; los HOMBRES DE GUERRA o militares profesionales; los HOMBRES DE LETRAS, desde entonces sinónimo de juristas, que por primera vez adquieren una importancia social notable al ser frecuentemente requeridos como consejeros ${ }^{42}$. Estos nuevos tipos humanos conforman una capa social de naturaleza hibrida y heterogénea desde el punto de vista de su procedencia y atribuciones, pero que constituyó una de las categorias más determinantes en el plano del desarrollo de las sociedades europeas, porque eran consecuencia de las nuevas situaciones.

A pesar de ello, el Renacimiento confirmó las estructuras sociales anteriores e incluso las reforzó al admitir en la nobleza a quienes aspiraban a entrar en ella por fortuna. Los asi ennoblecidos hicieron que poco a poco se adoptaran valores que no procedian de la tradición caballeresca, pero en contrapartida, asimilaron otros valores de la nobleza.

La renovación de la nobleza es un fenómeno que se puede seguir en Europa a lo largo de los siglos xIV y xV. A este respecto no se pueden establecer cortes, pues se trata de una movilidad social vertical que se presenta como una de las características del Renacimiento. El Renacimiento condujo tanto en Venecia como en Inglaterra, España y Alemania a una brillante consolidación de la nobleza, y no al triunfo de la burguesia como se piensa; confirmó la jerarquía tradicional, pues lo que la nobleza perdió en poder político, lo ganó en poder económico, en prestigio y en influencia cultural. El nexo jerárquico predominó en el Renacimiento sobre cualquier tipo de relación horizontal: "le troisième état", denominación francesa que correspondia a los "comunes" en Inglaterra y a los pecheros en España, designaba a toda la población que no estaba incluida en el clero ni en la nobleza, es decir, a la gran mayoría desasistida.

\footnotetext{
${ }^{41}$ Maravall, J. A., "La concepción del saber en una sociedad tradicional», en Estudios de Historia del Pensamiento Español, Serie Primera: Edad Media. Madrid 1973 (2." ed.), págs. 215-273.

${ }_{42}$ Pelorson, Jean-Marc, Les Letrados, juristes castillans sous Philippe 1II: recherches sur leur place dans la société, la culture et l'état. Poitiers 1980. Y también Anderson, Perry, Op. cit., págs. 28-43-48.
} 
La nueva jerarquía no se basaba ya únicamente en vínculos de dependencia personal, sino en la gestión privilegiada del poder, pero resultaba tan rigida como la feudal. Habia, además, comenzado a surgir la instancia superior ante la cual no cabia otra opción que doblegarse.

A pesar de la existencia de un estrato urbano de dimensiones considerables, que ocupaba un plano intermedio entre los grupos aristocráticos y el pueblo llano, lo que más llama la atención es la diferencia que se dio en el amplio abanico de rentas. Estas diferencias, fueron un gran obstáculo para la constitución de una verdadera mentalidad de clase media. La situación de los campesinos se agravó a finales de la época renacentista, siendo una contradicción que se repite en Francia, Italia, Inglaterra y España: se operó un ensanchamiento del abismo que separa a ricos y pobres tanto en la ciudad como en el campo y, en definitiva, a pesar de que los estratos intermedios de la sociedad se incrementaron numéricamente, no fueron ellos los que dieron el tono dominante a la sociedad sino la aristocracia, presentándose asi una contradicción evidente entre los principios esenciales del Renacimiento avalados por el culto a la razón y a la libertad ${ }^{43}$.

El Estado Moderno debe de ser analizado desde el punto de vista topológico, como un fenómeno que depende de otro de mayores proporciones y no como un hecho aislado y singular. La posición española dentro de la significación global del Estado Moderno no es ciertamente marginal, y el proceso de evolución de las Monarquías Europeas hacia la ampliación de esferas y mecanismos de poder, cuenta con la presencia puntual y en muchos aspectos anticipada de España como se deduce del análisis de la realidad política peninsular del siglo XV.

Durante los siglos XIV y $x V$ es posible constatar ( $y$ no solo en Castilla) una tendencia a buscar el fortalecimiento de poderes del soberano, que si bien se encuentra aún lejos del absolutismo, cuenta con la intervención creciente de instrumentos jurídicos; la creación de organismos al servicio de la Corona; y el tratamiento adecuado de instituciones tradicionales como las Cortes, factores todos ellos tendentes a soslayar particularismos en beneficio de la Corona.

Este fortalecimiento del poder monárquico en España supone un indice indudable de europeísmo y en tal sentido es posible hallar semejanzas suficientes que ajusten el caso español al modelo que desarrolló el mun-

${ }^{43}$ Delumeau, J., "Movilidad social: ricos y pobres en la época del Renacimiento" en LA Brousse, C. E.; Goubert, P.; le Goff, J.; Soboul, A. y otros. Ordenes, estamentos y clases, Madrid 1978. (Coloquio de Historia social), págs. 150-161. 
do occidental, pero al mismo tiempo la situación española registra diferencias sustanciales respecto al modelo europeo, tantas que aconsejan una vez más utilizar con escepticismo el sistema teórico, que por otra parte no ofrece un modelo puro dadas las diferencias con que se resuelve proceso en las distintas zonas de la Europa renacentista.

Es evidente que la dinámica social del siglo xv español se gesta en torno al desarrollo de dos conceptos que marcan su dialéctica: el fortalecimiento del poder del rey por un lado, y el individualismo renacentista por otro. Un análisis cuidadoso de la realidad peninsular en los planos politico y social detecta corrientes, movimientos y sucesos que se inscriben "per se" en la diáspora renacentista, pero no cabe al mismo tiempo situarlos dentro de una línea de evolución progresiva, puesto que el camino hacia el nuevo orden que supone la modernidad está cuajado de elementos arcaizantes que lo interrumpen y lo contradicen.

Si se puede afirmar con certeza que en la Espar̃a del siglo xv se dan los requisitos necesarios para poder asegurar que su desarrollo cae de lleno dentro de la evolución propia de un Estado Moderno, es necesario matizarlos:

A) El concepto de nación (una de las características del Estado Moderno) como ente aglutinante de diferentes colectivos, es una realidad inexistente en la España del siglo xv. Si bien la palabra Hispania fue de uso corriente a lo largo de toda la Edad Media para designar a la Peninsula Ibérica como unidad geográfica; y si bien los marinos valencianos y aragoneses se consideraban desde el punto de vista geográfico habitantes de España aunque procediesen de distintos puntos de la Peninsula hablaban de "volver a España” ${ }^{44}$. La España medieval responde a una idea no uniforme y si de realidades diversas a cargo de los distintos reinos que cohabitaban en el territorio peninsular; tratándose de la misma superposición que se dio en otros paises de Europa. En la España del siglo $x v$ no hay unidad política ni tampoco unidad económica, social ni humana: Castilla-León, Aragón (con Cataluña), Valencia, Navarra, Portugal y Granada son los reinos que componen el variopinto mosaico Peninsular, siendo tal diversidad la primera realidad con la que hay que contar a la hora de acercarnos a la

${ }^{44}$ Kamen, Henry, Una sociedad conflictiva: España 1469-1714. Madrid 1984, págs. 245-247- 
España bajomedieval ${ }^{45}$. De entre las monarquías citadas, son Castilla y Aragón las más representativas y al mismo tiempo los que mantienen entre si una diferenciación más acusada. Ambos reinos protagonizan la historia social y económica del siglo $x \mathrm{~V}$ al que llegan con un bagaje estructural diferente, marcado por el grado de atención que cada uno aportó a la problemática dual de la Reconquista y el Feudalismo. Mientras Aragón, como zona de influencia de los Francos, se había organizado sobre principios netamente feudales, en Castilla nada o casi nada de esto habia ocurrido ya que la atención preferente se habia mantenido hacia el hecho de la Reconquista, que a su vez habia necesitado del concierto directo y no diferido de las fuerzas fácticas con las fuerzas de la realeza ${ }^{46}$.

B) La unidad territorial, otro de los elementos esenciales del Estado Moderno, se realizó en España en fecha tardia y sobre bases absolutamente superficiales ${ }^{47}$. En Aragón y Navarra habia sistemas parlamentarios activos, mientras que las provincias vascas gozaban de una situación fiscal diferenciada dentro de la Península. En la propia Castilla habia enormes restricciones dentro de las que funcionaba el gobierno a principio de la Edad Moderna, dado que una considerable proporción de territorio escapaba a la jurisdicción real, por pertenecer a la jurisdicción señorial y dada la existencia de elementos feudalizantes, expresados a través de instituciones como la Santa Hermandad o los Gremios, que retenían para sí parcelas de jurisdicción detraidas del poder politico supremo ${ }^{48}$. El rey no disponia, salvo en la capital, de algo que pudiera denominarse fuerza de orden público, como lo afirma el hecho de que para gobernar fuera de la Corte hubiera de confiar en la cooperación de las élites dirigentes, es decir, en las oligarquias locales. La restricción más evidente del poder real era la parte del territorio que no controlaba el rey, de cuya importante proporción dan una idea las siguientes cifras: en el siglo xvi, en la provincia de Salamanca, el 63 por 100 del territorio y más del 6 por 100 de sus habitantes pertenecia a la jurisdicción de nobles.

${ }^{4 h}$ Elliot, H. J., La España Imperial. Barcelona 1965, pág. 13, citando a Konetzke, Richard, en El Imperio Español. Madrid 1946, pág. 81.

${ }^{46}$ Ladero Quesada, M. A., España en 1492 en David Viñas (comp.): Historia de América Latina, vol. 1. Madrid 1978.

${ }_{47}$ De manera completa no se realizó hasta el siglo xvil.

${ }^{48}$ Perez-Prendes, J. M., Derecho y Poder. Separata de la obra HISTORIA General DE ESPAÑA Y AMÉRICA (Eds. RIALP), t. IV, págs. 62-64 (de la Separata). 
La situación era parecida en toda España: en Valencia tan sólo 73 pueblos eran de realengo mientras que más de 300 eran de señorio. En Aragón sólo tenia el rey jurisdicción sobre 498 de los 1.183 centros de población existentes ${ }^{49}$.

Por otra parte, la unión de Aragón y Castilla sólo podia venir de la mano de la aplicación de una politica dinástica, dada la existencia de argumentos históricos y económicos, tanto disgregadores como aglutinantes de fuerzas activas que permitian intentar la asociación de ambas coronas bajo condiciones favorables. La alianza matrimonial de Fernando de Aragón e Isabel de Castilla fue mejor vista en Aragón dadas las dificultades económicas que atravesaba el reino, pero al mismo tiempo, ofrecia la ayuda que Isabel necesitaba para legitimar su dudosa herencia. De hecho se trataba de la unión de dos paises con historias y caracteres distintos que se hallaban en estados diferentes de desarrollo histórico ${ }^{50}$.

La superioridad demográfica de las regiones centrales constituye una de las claves esenciales para entender que la monarquía de los Reyes Católicos, presentase un claro signo castellano. En Castilla existian unas mejores bases para poder sistematizar las fuerzas politicas hacia una monarquía centralizada puesto que la evolución política y la evolución mercantil son fenómenos paralelos como anteriormente ha quedado señalado. A pesar de la unión personal de Fernando e Isabel Aragón y Castilla, siguieron siendo esferas politicas independientes, permaneciendo cada una en su propio compartimento, regido por sus propias leyes como lo revelan tanto el contrato matrimonial, celebrado entre los dos cónyuges en 1469, como el testamento de Isabel. Ambos documentos revelan un concepto esencialmente patrimonialista del Estado.

Tratar de aplicar el planteamiento teórico del Estado Moderno y del Renacimiento al escenario de lo español obliga a moverse dentro de unos márgenes específicos de tiempo y lugar. El origen del Estado Moderno español ha sido con frecuencia considerado como una caracteristica exclusiva del reinado de los Reyes Católicos. Pero tal consideración implica una ubicación excesivamente restringida de un fenómeno que tiene marcados sus origenes en Castilla, de manera clara, ya en el reinado de Alfonso $X^{51}$ y que experimentó una intensificación creciente desde los primeros gobiernos de la dinastia Trastamara.

${ }^{49}$ Hillgart, J. M. Los reinos Hispánicos 1250-1516. México 1979, pág. 133

50) ElLIOT, Op. cit., pág. 13.

${ }^{51}$ Pérez-Prendes, J. M., Derecho y Poder. Trabajo citado en Nota 5 Supra; y, Ballesteros Beretta, A., Alfonso $X$ el Sabio. Barcelona 1984. 
Fundamentos metodológicos para el estudio de las instituciones ...

Para la Historia tradicional la ruptura entre los tiempos medievales y modernos ha tenido en Castilla su expresión más genuina en el contraste ofrecido por los reinados de Enrique IV (cuajado de facciones nobiliarias) y el de los Reyes Católicos (fustigadores de los poderosos). Situadas así las cosas, resulta dificil poder hallar conexiones entre los fenómenos ocurridos en ambas etapas. Se trata sin duda de una visión simplista pues, resulta evidente que la problemática social castellana de la segunda mitad del siglo xv participa de nexos comunes debido a que es la manifestación de un proceso de más largo alcance y más generalizante: la formación del Estado Moderno. Situar una barrera que separe a la Edad Media y a la Moderna en la época de los Reyes Católicos entraña el riesgo de interpretar su reinado como plenamente perteneciente a los nuevos tiempos y además constituye una desventaja ante la que hay que proceder con cautela. En la problemática social del reino castellano no existe la pretendida barrera situada entre los reinados mencionados, como podrá comprobarse. En el reinado de Enrique IV hay signos de modernidad, del mismo modo que los hay de medievalidad en el de los Reyes Católicos ${ }^{52}$. El desorden era accidental; los principios en que habia de basarse la restauración monárquica eran sólidos y permanentes. Las transformaciones sociales que tuvieron lugar en Castilla en los siglos XIV $y \mathrm{xV}$, corren a cargo del fortalecimiento de la monarquia y de sus órganos de gobierno, a través del perfeccionamiento de un aparato institucional en el que se busca la seguridad y la pervivencia del sistema.

Esta tendencia ascendente de la monarquia, discurre al mismo tiempo paralela al engrandecimiento de la nobleza que consolida su propiedad territorial feudal gracias a la proliferación de señoríos y a la posibilidad de transmitirlos indivisos desde la plena Edad Media. El proceso señorializador fue el punto de partida de la configuración de unas estructuras sociales que con ligeros retoques tuvieron continuidad hasta el siglo XIX en Castilla, esto viene a probar que el tratamiento que tuvo la nobleza por parte de la monarquia no fue el de un estorbo, ni tampoco el de un instrumento en manos del poder real. A través de la relación que entablaron la nobleza y la nueva monarquia, fue posible que quedara reproducido el equilibrio originario entre el soberano feudal y sus vasallos, eso si, dentro de un marco complejo y eficaz. A cambio del sometimiento los Reyes Católicos reconocen el papel social de la aristocracia, regulan las normas de acceso a la hidalguia ${ }^{53}$, favorecen la constitución de

\footnotetext{
5. Valdeon Baruque, J., "ila última revuelta medieval?", Cuadernos de Historia 16, n." 24. Madrid 1985, pág. 4

${ }^{33}$ Leyes de Córdoba de 1492, en Los Códigos Españoles Concordados y Anotados. T. VI. Madrid 1849
} 
mayorazgos ${ }^{54} \mathrm{y}$, la institución básica del señorio fue respetada en líneas generales. Las esperanzas de los pueblos de que una monarquia fuerte les permitiera diluir aquel vasallaje se ven defraudadas. Los fundamentos del sistema se mantuvieron incólumes.

La aparente contradicción que implica el entendimiento entre dos fuerzas que en momentos episódicos se presentan como rivales queda resuelta en el resultado de la lucha. Tanto la nobleza como la monarquia resultaron triunfantes en Castilla; sus diferencias eran menos profundas de lo que a simple vista pudiera parecer, ya que defendian los mismos intereses. El resultado fue una curiosa paradoja que permitió el fortalecimiento económico y social de la nobleza de forma tal que el rey pudo cobrar su poder absoluto ${ }^{55}$. Semejante solución fue posible mediante la adaptación del resto de las fuerzas sociales que quedaron necesariamente relegadas dentro de la nueva lógica del poder. La concepción horizontal medieval, dentro de la que fue posible que algunas esferas de poder como el municipio o las ciudades pudieran esgrimir sus bien ganados privilegios tradicionales, fue sustituida por una concepción vertical a medida que las atribuciones del absolutismo iban abriéndose paso y ganando terreno. Tal pérdida de atribuciones se ha achacado con demasiada frecuencia a la falta de potencia y de organización que presentaban el resto de las fuerzas sociales que no fuera la nobleza, pero ello no es totalmente cierto, o no lo es en todos los casos. La táctica con la nobleza fue por otra parte la misma que se siguió con respecto a otras fuerzas sociales: reducirla a la obediencia y hacerla colaborar en la trama común. Si en el ámbito rural puede aducirse la existencia de colectivos inconexos a cargo de la heterogeneidad del campesinado, no es posible aplicar las mismas referencias al marco de la vida urbana, donde gracias a la expansión demográfica y al amparo del mercantilismo habian florecido elementos suficientes como para inspirar y canalizar la defensa de intereses comunes. El fortalecimiento del poder de la realeza se hizo en detrimento de otros sectores sociales que resultaron claramente perjudicados, habiendo sido este tema suficientemente analizado en los trabajos de Reyna Pastor ${ }^{56}$, Julio Valdeón ${ }^{\text {bl }} y$, Esteban Sarasa ${ }^{58}$.

\footnotetext{
:4 Leyes de Toro de 1505, en Los Códigos Españoles Concordados y Anotados. T. VI. Madrid 1849.

so Suarez Fernandez, L., Nobleza y Monarquía. Puntos de vista sobre la Historia Politica castellana del siglo xv. Valladolid 1975, pág. 11.

56 Pastor Togneri, Reyna, "Las primeras rebeliones en León y Castilla del siglo xIII», en Conflictos sociales y estancamiento económico de la España medieval. Barcelona 1973, págs. 13-101.

if VAlDeON Baruoue, J., "Tensiones sociales en los siglos xIV y XV, Actas de las / Jornadas
} 
Fundamentos metodológicos para el estudio de las instituciones ...

El choque de la alta nobleza con los patriciados urbanos se produjo de manera frontal, y en medio de él la Corona apostó por la nobleza. La victoria fundamental de la monarquia sobre la resistencia corporativa fue la derrota de las ciudades ${ }^{59}$. Algunas ciudades en esta época estuvieron en posición de convertirse en un evidente peligro para la Corona, de haberse producido un enfrentamiento directo entre ambas, siendo ésta la razón por la que la operación de despojo se realiza de manera paulatina mediante una politica de confusiones que abarca simultáneamente la decapitación/remodelación de instituciones de raigambre genuinamente medieval (las Hermandades o las Cortes), con el reconocimiento de su relevancia a través de concesiones puntuales como fue la imposición del sistema recaudatorio del Encabezamiento. La simplificación politica que entraña la proyección rectilínea de la nueva lógica del poder que se instauró en Europa con el Estado Moderno marcó su historia en los siglos venideros ${ }^{60}$.

Los beneficios que obtuvo la nobleza, a lo largo del proceso de formación del Estado Moderno, fueron grandes. El pacto tácito que selló la alianza entre monarquia y nobleza, desembocó en una supremacia de la aristocracia dentro del panorama económico. La legitimidad de la nobleza, reposa en la creencia de un orden que acepta la desigualdad como una necesidad para la organización de una sociedad fundamentada más sobre la fe que sobre la ciencia; más sobre la tradición que sobre el progreso; más sobre la familia que sobre el individuo; más apoyada en la continuidad biológica de las generaciones que en la lógica del espiritu de justicia igualitaria. Se perfila pues, una sociedad de base aristocrática que perdudará hasta la llustración.

de Metodologia aplicada a las ciencias históricas, II. Santiago de Compostela 1975, págs. 257-281. Del mismo autor, Los conflictos sociales en el reino de Castilla en los siglos XIV y XV. Madrid 1975.

${ }^{58}$ Sarasa Sanchez, E., Sociedad y conflictos sociales en Aragón: siglos xil-xv. (Estudios de poder y conflictos de clase). Madrid 1981.

${ }_{59}$ Anderson, Perry, El estado absolutista. Madrid 1979, pág. 55.

${ }^{60}$ TENENTI, A., La formación del mundo moderno. Barcelona 1985, pág. 26. 